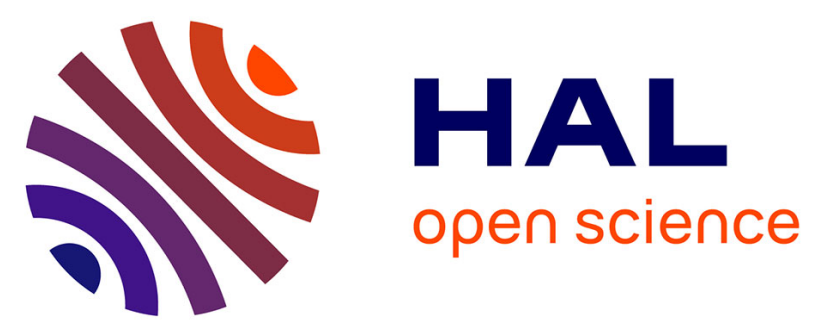

\title{
MR imaging, targeting and characterization of pulmonary fibrosis using intra-tracheal administration of gadolinium-based nanoparticles
}

Nawal Tassali, Andrea Bianchi, François Lux, Gérard Raffard, Stephane Sanchez, Olivier Tillement, Yannick Crémillieux

\section{To cite this version:}

Nawal Tassali, Andrea Bianchi, François Lux, Gérard Raffard, Stephane Sanchez, et al.. MR imaging, targeting and characterization of pulmonary fibrosis using intra-tracheal administration of gadolinium-based nanoparticles. Contrast Media and Molecular Imaging, 2016, 11 (5), pp.396-404. 10.1002/cmmi.1703 . hal-02404863

\section{HAL Id: hal-02404863 \\ https://cnrs.hal.science/hal-02404863}

Submitted on 11 Dec 2019

HAL is a multi-disciplinary open access archive for the deposit and dissemination of scientific research documents, whether they are published or not. The documents may come from teaching and research institutions in France or abroad, or from public or private research centers.
L'archive ouverte pluridisciplinaire HAL, est destinée au dépôt et à la diffusion de documents scientifiques de niveau recherche, publiés ou non, émanant des établissements d'enseignement et de recherche français ou étrangers, des laboratoires publics ou privés. 


\title{
MR imaging, targeting and characterization of pulmonary fibrosis using intra-tracheal administration of gadolinium-based nanoparticles
}

\author{
Nawal Tassali $i^{a *}$, Andrea Bianchi ${ }^{a}$, François Lux ${ }^{b}$, Gérard Raffardd ${ }^{a}$, \\ Stéphane Sanchez ${ }^{a}$, Olivier Tillement ${ }^{b}$ and Yannick Crémillieux ${ }^{a}$
}

\begin{abstract}
Idiopathic pulmonary fibrosis is a devastating disease. Animal models are critical to develop new diagnostic approaches. We investigate here whether the application of an ultra-short echo time MRI sequence combined with the intra-tracheal administration of Gd-based nanoparticles can help to visualize and characterize pulmonary fibrosis in mice. 21 mice were imaged. Treated mice were administered bleomycin. MRI was used for longitudinal detection of bleomycin-induced lung injury from Day 1 up to Day 60. On Day 30, all mice received nanoparticles and MR images were acquired. A signal enhancement of $120 \%$ and $50 \%$ in fibrotic lesions and healthy tissues respectively was obtained. A twofold increase of contrast-to-noise ratio between fibrotic and healthy tissue was also observed, leading to a more accurate delineation of the extent of fibrosis. The elimination time constant of the nanoparticles was $\mathbf{5 4 \%}$ higher in fibrotic lesions. Bleomycin-induced lung injury can be monitored using MRI. Intra-tracheal administration of Gd-based nanoparticles enabled us to enhance fibrotic tissue in lungs but also to extract imaging biomarkers that quantify elimination and diffusion of contrast agents and can characterize fibrotic tissue. The added value of MRI associated with pulmonary administration of contrast agents is key to better understand the lung fibrotic process and monitor drug response in pre-clinical studies, which will be valuable for translational applications. Copyright @ 2016 John Wiley \& Sons, Ltd.
\end{abstract}

Keywords: MRI; Gadolinium; fibrosis; targeting; intra-tracheal administration; nanoparticles; contrast agent

\section{INTRODUCTION}

Idiopathic pulmonary fibrosis (IPF) is a chronic, progressive and ultimately lethal disease characterized by excessive fibroblast and extracellular matrix (ECM) proliferation and accumulation of inflammatory cells. These pathological alterations result, among other things, in the thickening of the blood-air barrier and in peripheral and basal honeycomb-like structures visible on radiological images $(1,2)$. Following the diagnosis of the disease, the mean life expectancy is low, ranging between two and four years, with patients' death mostly due to respiratory failure (3-5). Although sometimes considered as a rare disease, it is estimated that IPF affects at least five million people worldwide (6). No efficient cure for IPF is available at the moment, and treatments essentially aim at slowing down the progression of the disease, reducing the symptoms and improving the comfort of the patients $(7,8)$.

Considering the poor prognosis of this disease and the absence of efficacious treatments, the development of early and sensitive diagnostic tools and follow-up techniques are essential to monitor the evolution of the disease and to assess the efficacy of therapies in animal models of lung fibrosis. The most frequently used animal model of IPF is the bleomycininduced lung fibrosis in rodents. In this model, bleomycin, an antibiotic used as anticancer agent and potential inducer of pulmonary fibrosis in patients, is administered to the animal lungs through the endotracheal route $(9,10)$.
Radiological X-rays and high resolution computed tomography are the usual imaging techniques for the diagnosis of IPF. MRI in lungs is impeded by strong limitations such as very short apparent transverse time $\left(T_{2}^{*}\right)$, low spin density and motion artefacts (11-14). Despite these difficulties for imaging normal or pathological lung tissue, MRI remains an attractive imaging tool when considering the absence of ionizing radiation, the excellent soft tissue contrast and the large choice of available commercial or pre-clinical contrast agents. As a matter of fact, during the last decade several pre-clinical MRI studies have demonstrated the potential of MRI for assessing the presence and the extent of fibrosis in experimental animal models of IPF (15-19).

In this work, we investigated whether the application of a $T_{1}$-weighted ultra-short echo time (UTE) MRI sequence combined with the intra-tracheal administration of gadolinium (Gd)-based nanoparticles, referred to hereafter as USRP (ultra-small rigid

\footnotetext{
* Correspondence to: N. Tassali, Centre de Résonance Magnétique des Systèmes Biologiques, CNRS UMR 5536, Université de Bordeaux, Bordeaux, France. E-mail: nawal.tassali@gmail.com

a N. Tassali, A. Bianchi, G. Raffard, S. Sanchez, Y. Crémillieux Centre de Résonance Magnétique des Systèmes Biologiques, CNRS UMR 5536, Université de Bordeaux, Bordeaux, France

b F. Lux, O. Tillement

Institut Lumière Matière, CNRS UMR 5306, Université Claude Bernard, Villeurbanne, France
} 
platform), can help to visualize and characterize fibrotic regions in the lungs. To this end, two mouse strains treated with bleomycin administered through the oropharyngeal aspiration (OA) route were investigated. The MRI signal enhancement $(\mathrm{SE})$, the contrast-to-noise ratio (CNR) and the biodistribution imaging of the nanoparticles were measured and compared between the bleomycin-treated group and the saline control group. The findings of the study demonstrate the potential of Gd-based nanoparticles for passive targeting of lung fibrosis regions. This contrast-enhanced imaging protocol represents a new sensitive and quantitative tool for evaluating the extent of lung fibrosis and potentially for monitoring the efficacy of administered drugs for IPF treatment.

\section{RESULTS AND DISCUSSION}

The presence of lung fibrosis was successfully detected with MRI in all the bleomycin-treated mice from both strains C57BL/6 and $B A L B / c$. As reported in previous lung MRI studies $(10,15,16,20)$ performed on animal models of IPF, the bleomycin-induced lesions were essentially visualized in the central region of the lungs, whereas distal regions of the lung had normal appearance in the UTE images. The evolution of the lung fibrosis was monitored in vivo using UTE MRI up to 60 days after the end of the sensitization protocol described by Egger et al. (10). Typical follow-up lung UTE images, as shown in Fig. 1, exemplify the onset of hyperintense MRI signals in central regions of the lungs (between Day 0 and Day 10) and the persistence of these high signal intensities up to Day 60 .

Typical lung MRI images obtained in the two mouse strains on Day 30 after the last bleomycin administration are shown in Fig. 2B, C, E, F. In some animals (Fig. 2B), free-breathing UTE $M R I$ allowed the identification of hyperintense regions attributed to fibrotic lung tissues but failed to clearly delineate the contours of the lesions in some of them (Fig. 2E). In contrast, the intratracheal administration of USRPs enabled the detection of bleomycin-induced lesion tissues in all animals (Fig. 2C, F).

On Day 30, the maximum SE values were observed between 45 and 120 min following the administration of the nanoparticles. At $70 \mathrm{~min}$, the SE measured in ROls located in the hyperintense regions was equal to $1.11 \pm 0.2$ in bleomycin-treated C57BL/6 mice and to $1.13 \pm 0.3$ in bleomycin-treated BALB/c mice. For comparison, at 70 min the SE measured in ROls with normal appearance in pre-contrast UTE images of bleomycin-treated animals and in control animals were respectively equal to $0.42 \pm 0.1$ and to $0.81 \pm 0.4$ in $\mathrm{C} 57 \mathrm{BL} / 6$ mice and to $0.35 \pm 0.16$ and to $0.76 \pm 0.12$ in BALB/C mice. Values measured in hyperintense and normal appearance regions in bleomycin-treated animals were significantly different $(p<0.05)$.

In all the bleomycin-treated mice, the CNR before the administration of the nanoparticles was equal to $21.0 \pm 3.4$ for C57BL/ 6 mice and to $22.4 \pm 6.8$ for BALB/c mice. The maximum CNR values were observed around $120 \mathrm{~min}$ following the administration of the USRPs. At this moment, the CNR was equal to $36.8 \pm 6.8$ for $\mathrm{C} 57 \mathrm{BL} / 6$ mice and to $44.7 \pm 4.0$ for BALB/C mice. The increase of contrast to noise ratio $(\triangle C N R)$ in the identified fibrotic tissues $2 \mathrm{~h}$ after the intra-tracheal administration of $50 \mu \mathrm{L}$ of $50 \mathrm{mM}\left[\mathrm{Gd}^{3+}\right]$ USRP showed almost twofold higher values. Significant differences $(p<0.05)$ were observed between CNR values obtained before and $2 \mathrm{~h}$ after the contrast agent administration.

The assessment of fibrotic tissue pre and post administration of contrast agent solution yielded similar values for the total volume. As shown in Fig. 3, a good correlation between the two measurements was obtained. However, the volumes measured from the contrast-enhanced images were 25\% larger on average. The reproducibility of volume measurement was statistically better $(p=0.005)$ using the contrast-enhanced acquisitions, with standard deviations of $2.7 \mathrm{~mm}^{3}$ and $3.7 \mathrm{~mm}^{3}$ respectively for post and pre contrast agent administration.

As shown in Fig. 4, the one-compartment biodistribution model with first-order kinetics adequately fitted the evolution of the concentration of nanoparticles measured in the lungs

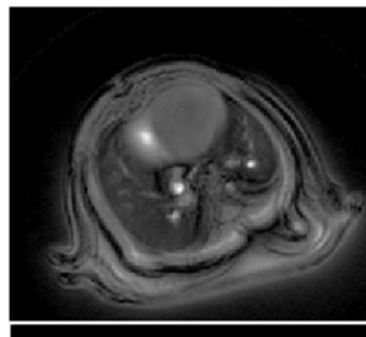

Do : Before bleomycin

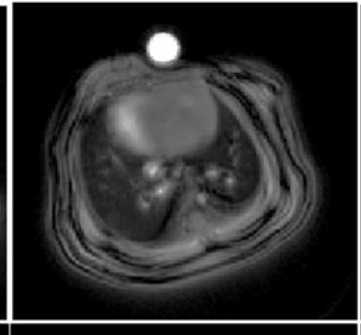

D2 after bleomycin

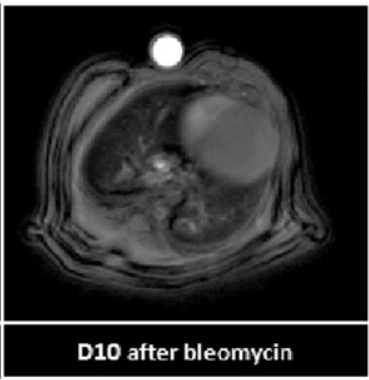

D10 after bleomycin

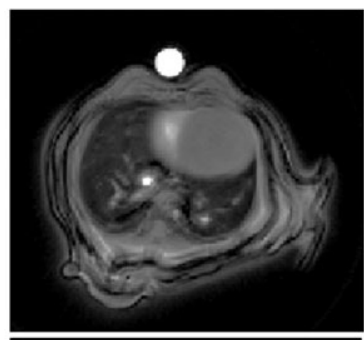

D30 after bleomycin

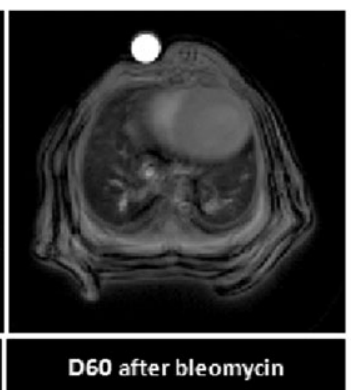

Figure 1. MRI follow-up of the bleomycin-induced injured lung up to Day 60. UTE-MRI axial slices of BALB/C mice before administration of bleomycin (D0) and 2 days (D2), 10 days (D10), 30 days (D30) and 60 days (D60) after the last administration of bleomycin. The arrows indicate fibrotic areas in the lungs. A $2.5 \mathrm{~mm}$ diameter reference tube containing a $1 \mathrm{mM}\left[\mathrm{Gd}^{3+}\right]$ USRP solution was positioned under the abdomen of the animal. 

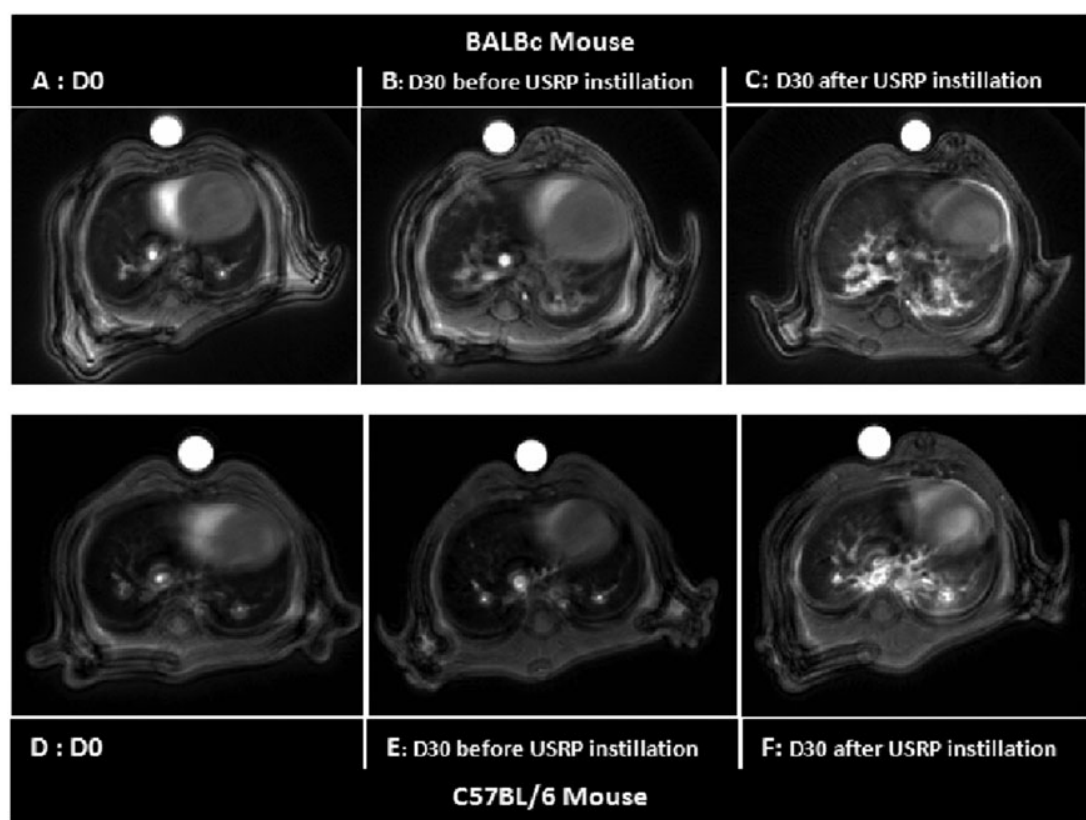

D : Do

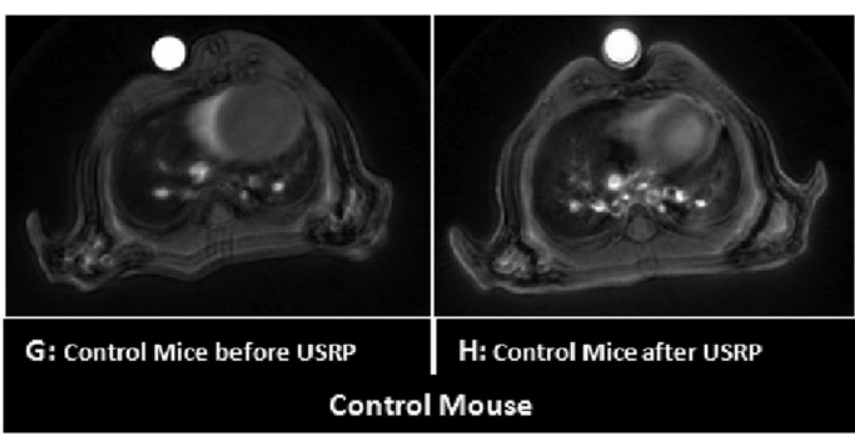

Figure 2. UTE-MRI axial slices of typical BALB/C mouse (A-C) and C57BL/6 mouse (D-F). A and D were acquired before the OA of bleomycin on Day 0. B and $E$ were obtained before intra-tracheal administration of $50 \mu \mathrm{L}$ of $50 \mathrm{mM}\left[\mathrm{Gd}^{3+}\right]$ USRP solution and images $C$ and $\mathrm{F}$ were acquired $70 \mathrm{~min}$ and $75 \mathrm{~min}$ respectively after intra-tracheal administration on Day 30. A $110 \%$ and a $120 \%$ SE was obtained in fibrotic lesions of BALB/C and C57BL/6 mice respectively. $\mathrm{G}$ and $\mathrm{H}$ were obtained in C57BL/6 control mice: before intra-tracheal administration of $50 \mu \mathrm{L}$ of $50 \mathrm{mM}\left[\mathrm{Gd}^{3+}\right]$ contrast agent (G) and 70 min after intratracheal administration $(\mathrm{H})$. A $2.5 \mathrm{~mm}$ diameter reference tube containing a $1 \mathrm{mM}\left[\mathrm{Gd}^{3+}\right]$ USRP solution was positioned under the abdomen of the animal.

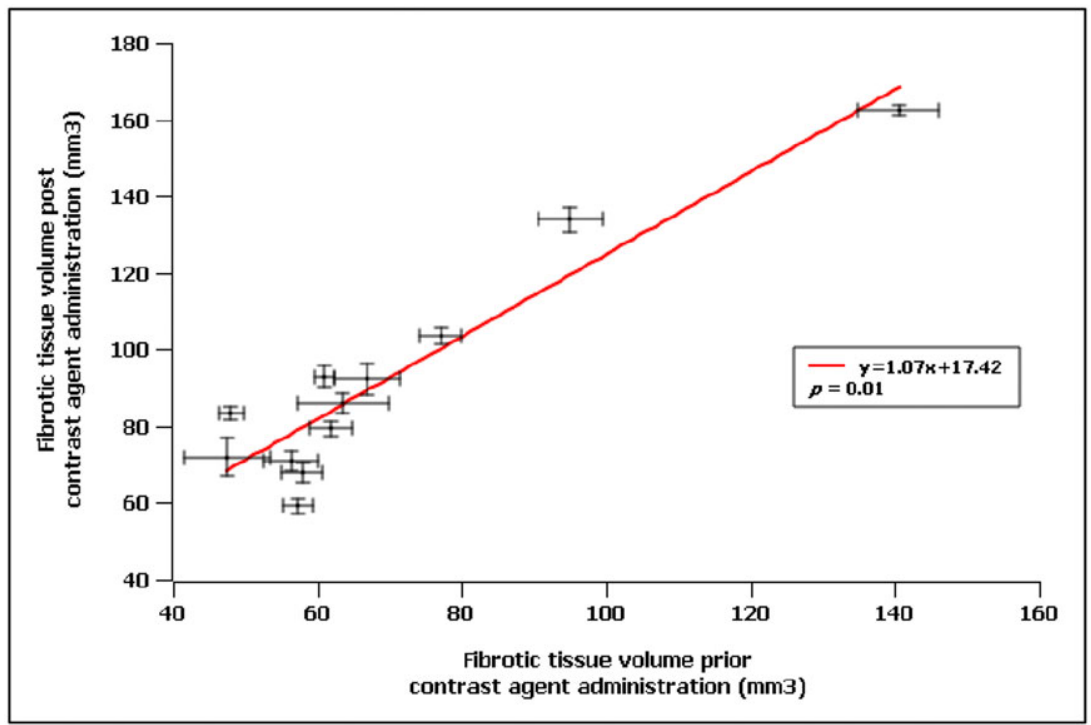

Figure 3. Fibrotic tissue volumes obtained from all individual mice pre and post intra-tracheal administration of contrast agent, shown respectively on horizontal and vertical axes. Error bars correspond to standard deviations obtained from two repeated volume measurements. 


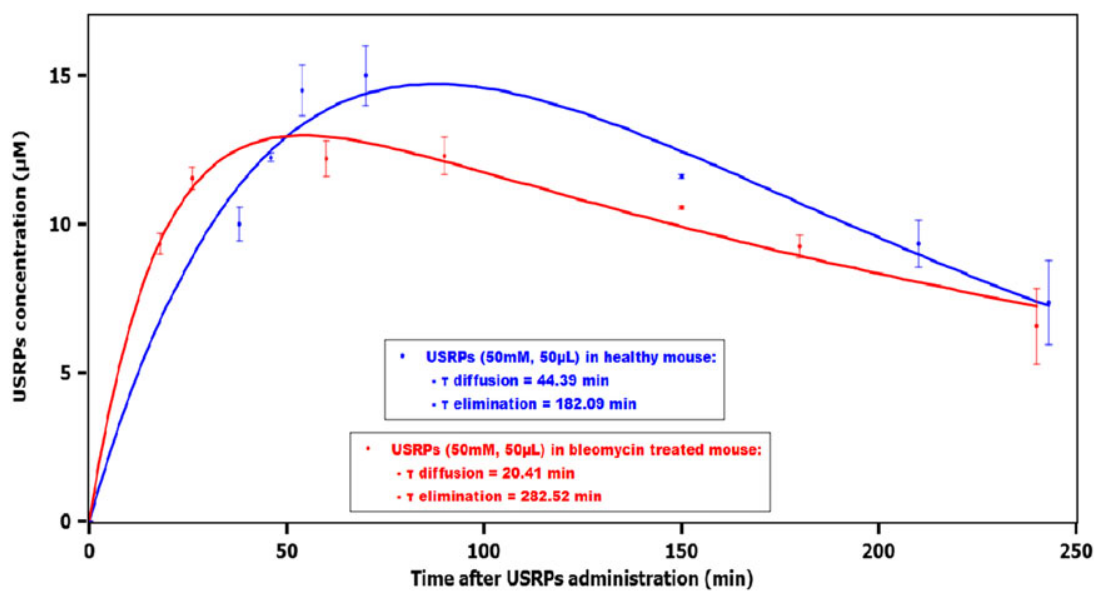

Figure 4. Typical fits of the evolution of the concentration of the nanoparticles in the lungs for $50 \mathrm{mM}\left[\mathrm{Gd}^{3+}\right]$ USRP solution for a bleomycin-injured C57BL/6 mouse on Day 30 after last bleomycin administration (in red) and for a healthy C57BL/6 mouse (in blue). The graphs are presented as mean \pm standard deviation.

after intra-tracheal administration of the USRPs in both healthy and bleomycin-injured animals.

In bleomycin-treated BALB/c mice the average value of the USRPS diffusion time constant, corresponding to the passage of the nanoparticles from airspace to lung tissue and pulmonary microcirculation, was equal to $26.0 \pm 5.5 \mathrm{~min}$, compared with the value of $44.5 \pm 9.4 \mathrm{~min}$ measured in the healthy mice. In C57BL/6 mice averaged diffusion values were equal to $26.0 \pm 5.5 \mathrm{~min}$ for bleomycin-treated mice and $41.7 \pm 8.1 \mathrm{~min}$ for healthy mice (Fig. 5). These differences in the diffusion time constant between the two groups of animals were not statistically significant ( $p=0.13$ and $p=0.14$ for BALB/C and C57BL/6 mice respectively).

In all bleomycin-treated mice, the average elimination time constant of the nanoparticles from the lung tissue and vascular compartment was significantly longer than that in healthy mice. In C57BL/6 mice, the elimination time values were equal to 250.6 $\pm 22.0 \mathrm{~min}$ for bleomycin-treated mice and $166.3 \pm 6.3 \mathrm{~min}$ for healthy mice (Fig. 5). In BALB/C mice, the elimination time values were equal to $249.7 \pm 26.1 \mathrm{~min}$ for bleomycin-treated mice and $159.6 \pm 13.6 \mathrm{~min}$ for healthy mice. This increase of elimination time constant was found to be statistically different between bleomycin and control groups ( $p=0.04$ and $p=0.02$ for BALB/C and $\mathrm{C} 57 \mathrm{BL} / 6$ mice respectively).

The presence of bleomycin-induced lung fibrosis was confirmed with histological analysis performed on mice on Day 30.
Typical histological images of bleomycin-treated and healthy C57BL/6 mice are shown in Fig. 6 for standard HE staining and Fig. 7 for picrosirius red staining. Increased cell density on HE-stained sections (Fig. 6) associated with collagen deposition on picrosirius-stained sections (Fig. 7) was observed in bleomycin-treated animals as compared with control animals. Similarly to MRI findings, the increased level of collagen was mostly located in central regions of the lungs of the animals.

The bleomycin-induced fibrotic lung injury was chosen in the present work, as a widely used and well characterized animal model of this disease. The advantages of the OA administration of bleomycin as described by Egger et al. are numerous. The technique is completely non-invasive compared with intratracheal administration, which can damage the tracheal route if the catheter placement is not done properly, especially for repeated administrations of solution. The method is easy to perform, reproducible, fast and allows a dose reduction of bleomycin compared with other techniques such as intra-nasal instillation (10). The intra-tracheal administration was preferred for the delivery of the nanoparticles. This approach allows a precise control of the number of nanoparticles delivered to the animals, and the administered solution has been shown to be uniformly distributed in the lungs (21).

The objective of this study was to assess the potential of intratracheally administered USRPs used as a new Gd-based contrast
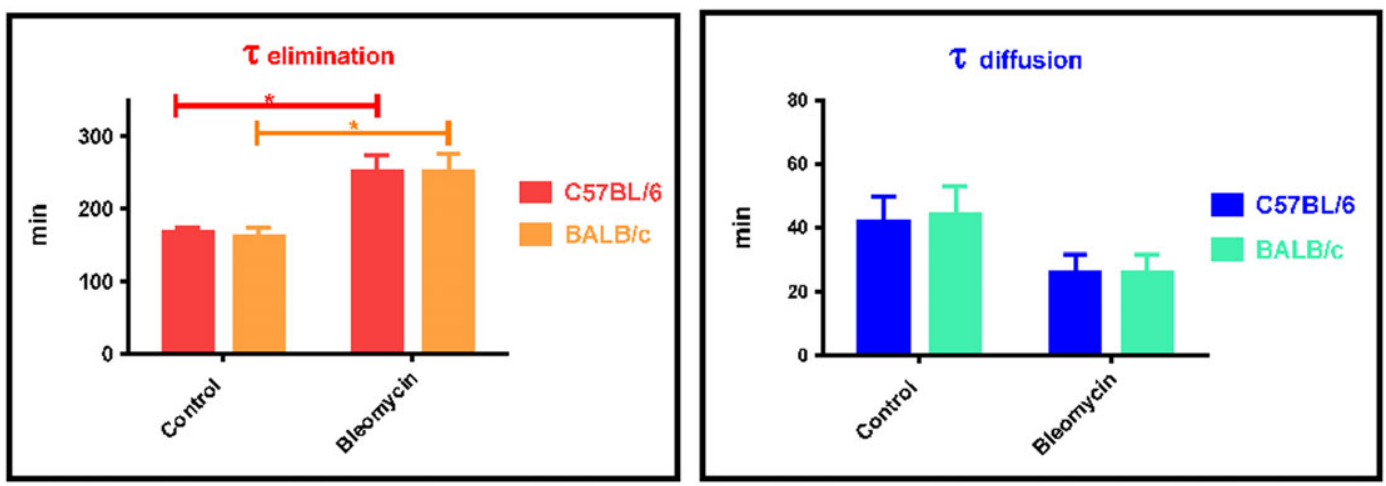

Figure 5. Elimination and diffusion average time constants obtained after the intra-tracheal administration of $50 \mathrm{mM}\left[\mathrm{Gd}^{3+}\right]$ USRP solution on Day 30 for C57BL/6 ( $n=8$ bleomycin treated, $n=5$ control) and BALB/c ( $n=4$ bleomycin treated, $n=4$ control) mice after the last administration of bleomycin. The asterisks indicate a significant difference with a probability $p<0.05$. The graphs are presented as mean \pm standard deviation of measurements made in two slices. 


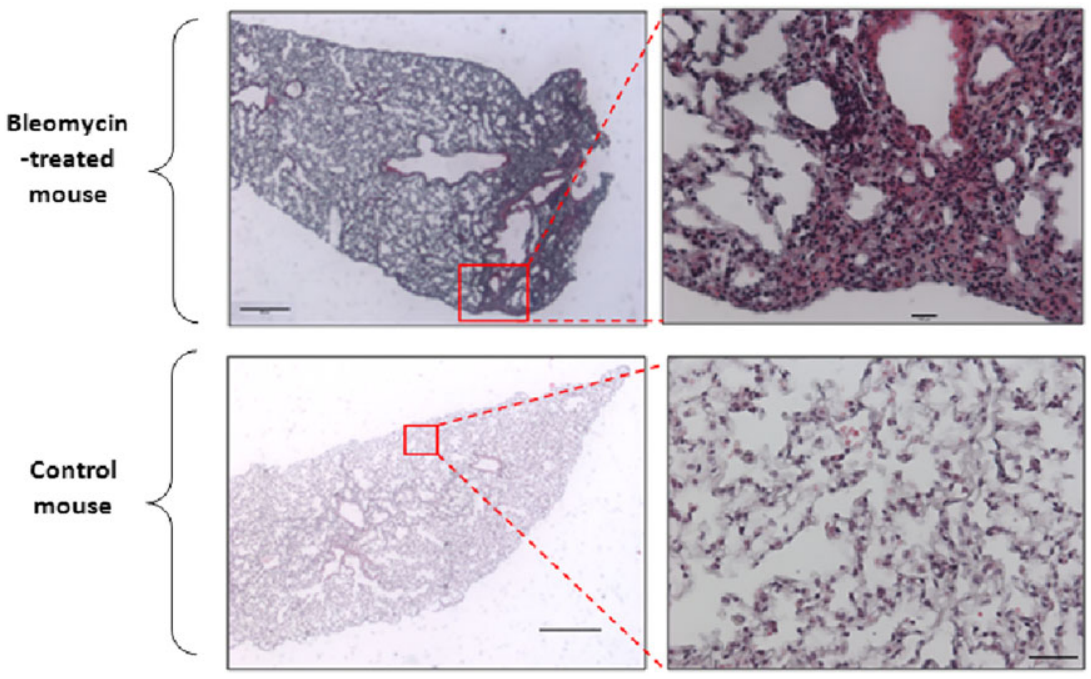

Figure 6. Typical examples of hematoxylin-eosin (HE) stains of fibrosis (top images) and control (bottom images) lung tissue. These HE stains from axial sections correspond to the MR image $2 \mathrm{E}$ (top fibrosis images) and $2 \mathrm{G}$ (bottom control images). The scale bars correspond to a magnified view $\times 25$ for left-hand images (scale bar $200 \mu \mathrm{m}$ for the top left image and $1000 \mu \mathrm{m}$ for the bottom left image) and to a magnified view $\times 200$ for right-hand images (scale bar $100 \mu \mathrm{m}$ for the top right image and $100 \mu \mathrm{m}$ for the bottom left image).

agent for enhancing and characterizing lung fibrotic tissues with MRI. Among all in vivo imaging modalities, MRI distinguishes itself with its ability of detecting subtle tissue changes, its noninvasiveness and the absence of ionizing radiation, facilitating the transfer into clinical practice. To circumvent the limitations of $M R I$ in the lung, the acquisitions were performed using radial UTE, an imaging sequence known to allow an early and rapid acquisition of the transverse NMR signal and to be less sensitive to motion $(22,23)$.

Hence, no respiratory or cardiac triggering was used in this study and free-breathing MRI acquisitions of the lungs were performed on the animals. The advantage of free-breathing imaging protocols is, first of all, to ensure a constant repetition time and thus identical image contrast weighting for all acquisitions. As a consequence, the effect of the Gd-based nanoparticles on the NMR signal intensity can be assessed and quantified longitudinally. As compared with respiratory gating or to mechanical ventilation, free-breathing acquisitions also result in shorter acquisition time, preferable for the follow-up of the biodistribution of the nanoparticles (21).

The Gd-based nanoparticles used in this study have been previously described as an intra-tracheally administered contrast agent in mice $(21,24)$. The authors reported a large, above $100 \%$, MRI SE in lung parenchyma following the administration of the nanoparticle solution $\left(50 \mu \mathrm{L}\right.$ of $\left.50 \mathrm{mM}\left[\mathrm{Gd}^{3+}\right]\right)$, similar to the one used in this study. They reported the absence of acute pulmonary (inflammatory cells and protein content in bronchoalveolar lavage fluid) and renal (creatinine concentration) inflammation markers. These nanoparticles were shown to be cleared by the kidneys before the final elimination through urine, without significant hepatic clearance. The mean half-life of the nanoparticles in the lungs of healthy mice was measured to be $149 \mathrm{~min}$ (Balb/c mice), in agreement with the results obtained in this study.

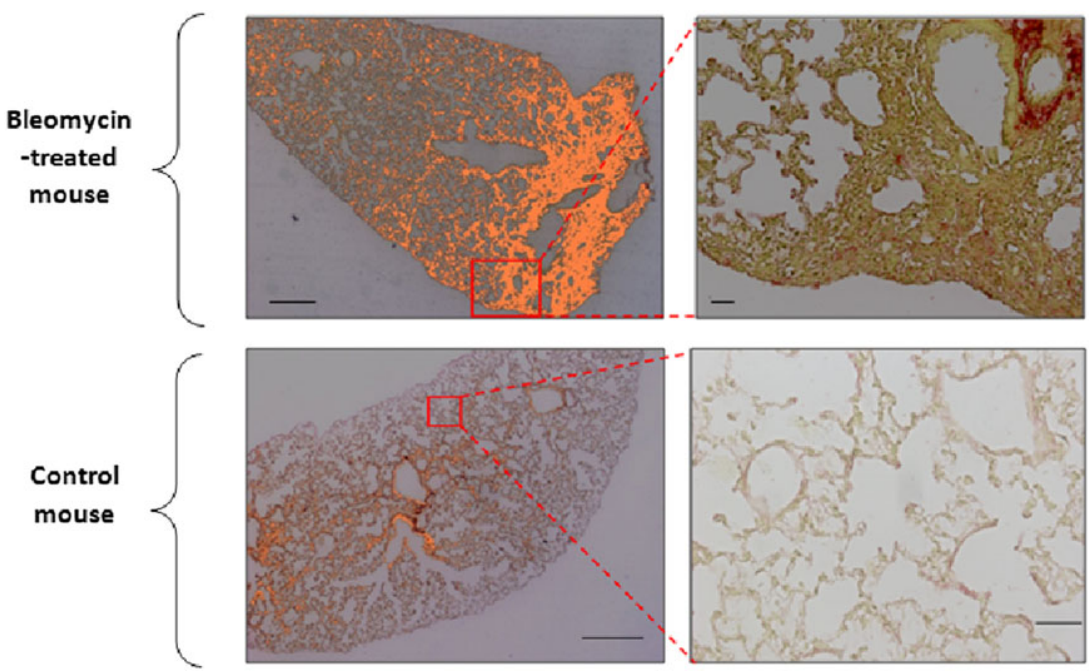

Figure 7. Picrosirius-stained lung sections corresponding to the same sections as in Fig. 6. Orange areas correspond to collagen stained by picrosirius red. The scale bars correspond to a magnified view $\times 25$ for the left-hand images (scale bar $200 \mu \mathrm{m}$ for the top left image and $1000 \mu \mathrm{m}$ for the bottom left image) and to a magnified view $\times 200$ for the right-hand images (scale bar $100 \mu \mathrm{m}$ for the top right image and $100 \mu \mathrm{m}$ for the bottom left image). 
The imaging protocol was validated on two mouse strains, $\mathrm{C} 57 \mathrm{BL} / 6$ and $\mathrm{BALB} / \mathrm{c}$. The former strain is known to be a high responder $(16,25)$ to bleomycin. The latter requires 10 times more bleomycin for fibrosis induction, and it represents the genetic background of many transgenic models (10). The measurements of this study in terms of elimination and diffusion constants show that the results presented are not strain dependent.

As widely reported in the literature $(15,16,26,27)$, during the first three weeks post bleomycin administrations, the animal model is characterized by an inflammatory phase with proliferation of collagen fibers and the presence of inflammatory mediators. This 3 week period is followed by a second phase characterized by the presence of profibrotic mediators and extended deposition of collagen fiber (26). The disease time period between days 21 and 60 can be considered as the most representative of human IPF in this bleomycin-induced animal model $(10,26,27)$.

For this reason, in this study the administration of the USRPs in fibrotic lungs was performed on Day 30 to avoid the inflammation regime and to focus on the fibrotic component of this animal model. It should be noted that the histological observations confirmed the extensive presence of collagen fibers in the lungs on Day 30.

Although free-breathing UTE MRI allowed the identification of abnormal and thickened lung tissues, the administration of nanoparticles proved to greatly improve the delineation of the fibrotic tissues, with SE values above $120 \%$ as compared with values around $40 \%$ in normal appearance lung tissue.

Several mechanisms might explain this differential SE in the fibrotic regions of the lungs. In healthy lung tissue, proteins contribute to the maintenance of a dry parenchyma, prevent increased fluid accumulation and guarantee efficient gas exchanges. In abnormal tissues, as in pulmonary fibrosis, there is an excess of ECM and of proteoglycan proteins contained in this matrix. Proteoglycans are known to be hydrophilic and therefore could have a non-negligible affinity with the nanoparticle solution $(28,29)$. It can thus be hypothesized that passive transport of the nanoparticle solution is facilitated by the widespread presence of hydrophilic protein linked to collagen and ECM deposition in bleomycin-induced lesions. Additionally, the larger concentration of extracellular matrix components might reduce the mobility of contrast agent nanoparticles, resulting in higher longitudinal relaxivity and increased NMR signal intensity.

The results of the study pointed out that the biodistribution of the nanoparticles greatly varies between the healthy and the bleomycin-treated groups. The longer elimination time constant of the USRPs in the fibrotic regions indicates a prolonged retention of the contrast agent within the diseased lung tissue. This can be related to the hampered access of the nanoparticles to the capillary blood vessels and their subsequent renal elimination. Notable studies in the field of hyperpolarized nuclei demonstrated an increase of transit time in the thickened air-tissue barrier in bleomycin lung injury animals. Using hyperpolarized ${ }^{129} \mathrm{Xe}$ MRI, Driehuys et al. developed a method to quantify gas-transfer efficiency, and were able to detect the ${ }^{129} \mathrm{Xe}$ signal in the gas phase of the airspace compartment and to follow the absorption of hyperpolarized xenon in the tissue parenchyma and in the red blood cells (RBCs). Their results showed a significantly increased time constant for the barrier and RBC signal replenishment with hyperpolarized gas in bleomycin-treated rat lungs (30).
The shortened diffusion time constant of the USRPs in the fibrosis animal group seems to indicate a fast passage and accumulation of the nanoparticles in diseased regions of the lung. Even though not statistically significant, this difference was systematically observed between bleomycin-treated and healthy animals. This observation might be related to the increased density of cellular components within fibrotic tissue. Again, hydrophilic proteoglycans might support this faster passage (31). It can then be hypothesized that the ultra-small contrast agent particles are rapidly diffusing from the airspaces to these fibrotic regions, where they contribute to signal intensity enhancement.

It is finally worth mentioning that the USRPs used in these experiments are designed to allow the grafting of functional groups. Specific compounds able to actively target some components of the ECM may be used in the near future. The combined use of the nanoparticles and the protocol developed in this study may therefore be employed to distinguish inflammation from purely fibrotic tissue, one of the most challenging and important issues for the development of efficacious treatments for IPF.

\section{CONCLUSIONS}

We showed in this study that high signal intensity enhancement and contrast-to-noise ratio in fibrotic lung tissue can be obtained when using intra-tracheal administration of non-targeting Gd-based nanoparticles. Due to their larger diameter, these nanoparticles offer a twofold higher longitudinal relaxivity per $\mathrm{Gd}^{3+}$ ion as compared with the clinically approved $\mathrm{Gd}$ chelates. In addition, their hydrodynamic diameter remains under $6 \mathrm{~nm}$, considered as an upper limit for a rapid translocation of particles from the airspace to the lung tissue and for later renal clearance (32). Further investigations are needed to validate the pharmacokinetic mechanisms hypothesized and to further understand the passive targeting and the behavior of the nanoparticles within bleomycin-induced injured lung.

The protocol developed in this study represents the first application of intra-tracheal MRI contrast agents for imaging lung fibrosis. The findings demonstrate the potential of this approach for visualizing and characterizing the presence of fibrotic tissue in bleomycin-treated animal models. The combined application of contrast agents and UTE MRI sequences may pave the way to the disentanglement of the complicated relation between inflammation and fibrosis, permitting better understanding of the pathophysiology of IPF. It could also help monitor the efficacy of antifibrotic drugs and therapeutic molecules targeting this life-threatening disease.

\section{EXPERIMENTAL}

\subsection{Animals}

Six-week-old BALB/C $(n=8)$ and C57BL/6 $(n=13)$ male mice were used for this study. Animals weighing $25.0 \pm 0.5 \mathrm{~g}$ were purchased from Elevage Janvier (Le Genest, France) and were acclimatized in a temperature-controlled environment under a $12 \mathrm{~h}$ normal phase light-dark illumination cycle for 1 week before the beginning of experiments. Tap water and food were freely available. Experiments were carried out following the INSERM (Institut National de la Santé et de la Recherche Médicale) guidelines regarding the fair treatment of animals with 
approval of the Comite d'Ethique en Expérimentation Animale de Bordeaux. At the end of the study, i.e. Day 60 for mice not included in histology protocols, the animals were euthanized by cervical dislocation.

\subsection{Administration of bleomycin}

Bleomycin-treated mice were administered bleomycin sulfate (Sigma Aldrich, Saint-Quentin Fallavier, France) $\left(0.1 \mathrm{mg} \mathrm{kg}^{-1}\right.$ for C57BL/ 6 mice and $1 \mathrm{mg} \mathrm{kg}^{-1}$ for BALB/C mice) in $40 \mu \mathrm{L}$ of saline via the OA route. OA was performed as described by De Vooght et al. (33). Briefly, mice were suspended vertically on a surgery board, the tongue was pulled out with a plier, and the liquid was dropped on the back of the tongue while the nose was gently closed. The procedure was repeated every day for six consecutive days as described by Egger et al. (10). A subgroup of mice (5 C57BL/6 and $4 \mathrm{BALB} / \mathrm{c}$ ) used as controls did not receive bleomycin.

\subsection{Nebulized Gd-based nanoparticles}

The Gd-based nanoparticle used throughout this study and referred as USRP is displayed in Fig. 8. These gadolinium1,4,7,10-tetraazacyclododecane-1,4,7,10-tetraacetic acid (DOTA)based nanoassemblies are composed of a polysiloxane core covalently linked, on average, to $10 \mathrm{Gd}$-DOTA species. The nanoparticles have a hydrodynamic diameter of about 3.0 $\pm 0.1 \mathrm{~nm}$. At $310 \mathrm{~K}$ the longitudinal relaxivity $r_{1}$ per gadolinium ion is equal to about $6.0 \mathrm{mM}^{-1} \mathrm{~s}^{-1}$ at $7 \mathrm{~T}$ (and thus $60 \mathrm{mM}^{-1}$ $\mathrm{s}^{-1}$ per nanoparticle). The mass of these nanoassemblies is about $8.5 \pm 1.0 \mathrm{kDa}$. Due to their hydrodynamic diameter being inferior to $5 \mathrm{~nm}$ the hepatic uptake following intravenous injection was measured below $0.15 \%$ of the injected dose using SPECT imaging and labeling with ${ }^{111}$ In (34). Further details about the synthesis and biodistribution of the particles following intratracheal administration can be found in References 34 and 35.

\subsection{MRI protocol}

A 2D ultra-short echo time (UTE) sequence (36-40) was used for the detection of bleomycin-induced lung injury in mice with the following parameters: 804 directions/256 sampled points, four averages, echo time $369 \mu \mathrm{s}$, field of view $3 \times 3 \mathrm{~cm}^{2}$, repetition time $140 \mathrm{~ms}$, acquisition bandwidth $50 \mathrm{kHz}$, matrix size
$256 \times 256$ and flip angle for the Gaussian-shaped RF excitation pulse $60^{\circ}$. The total acquisition time, for 10 axial slices of $1 \mathrm{~mm}$ thickness covering the entire lung, was equal to $7.5 \mathrm{~min}$. All acquisitions were obtained on spontaneously breathing animals; no triggering on the respiration or on the cardiac cycle was applied.

Mice were placed in the magnet in prone position in a homemade plastic holder and anesthetized with $2.5 \%$ isoflurane in a mixture of $\mathrm{O}_{2} / \mathrm{N}_{2} \mathrm{O}(80: 20)$ via a facial mask. The respiratory cycle was monitored using a pressure sensor placed on the animal abdomen. The images were acquired with a 7T Bruker spectrometer using a transmitter-receiver quadrature coil of $25 \mathrm{~mm}$ inner diameter (Bruker, Ettlingen, Germany) and a gradient system with maximum magnetic field gradient amplitude of $600 \mathrm{mT} \mathrm{m}^{-1}$.

Lung MRI acquisitions were performed before and on different days following the last bleomycin administration (Days 1, 2, 10, 30 and 60).

On Day $30,50 \mu \mathrm{L}$ of a $50 \mathrm{mM}\left[\mathrm{Gd}^{3+}\right]$ USRP solution was intratracheally administered into the lungs of C57BL/6 mice and $\mathrm{BALB} / \mathrm{c}$ mice for both bleomycin-treated and control groups. The administration of the nanoparticles followed the protocol previously described in Reference 35. UTE-MR images of healthy and injured lungs were acquired before and at different times after the nanoparticle instillation (from $15 \mathrm{~min}$ up to $4 \mathrm{~h}$ ).

\subsection{Image analysis and quantification}

All the images were reconstructed using ParaVision 5.1 (Bruker, Ettlingen, Germany) and analyzed using the free software MIPAV (Medical Image Processing, Analysis, and Visualization, $\mathrm{NIH}$, Baltimore, MD, USA). For each animal and each image, fibrotic tissues were identified and regions of interest (ROIs) approximately $2.5 \mathrm{~mm}$ in diameter were manually drawn in fibrotic and in healthy tissues of the parenchyma to measure an average signal. A $2.5 \mathrm{~mm}$ diameter reference tube containing a $1 \mathrm{mM}$ $\left[\mathrm{Gd}^{3+}\right]$ USRP solution was positioned under the abdomen of the animal. The noise was defined as the standard deviation of the mean signal of an ROI selected in this reference. The signal-to-noise ratio (SNR) was computed as the average signal measured in an ROI of the lung divided by the noise value. The SE was computed as the difference between the SNR in the lungs after administration of the USRPs and SNR before the

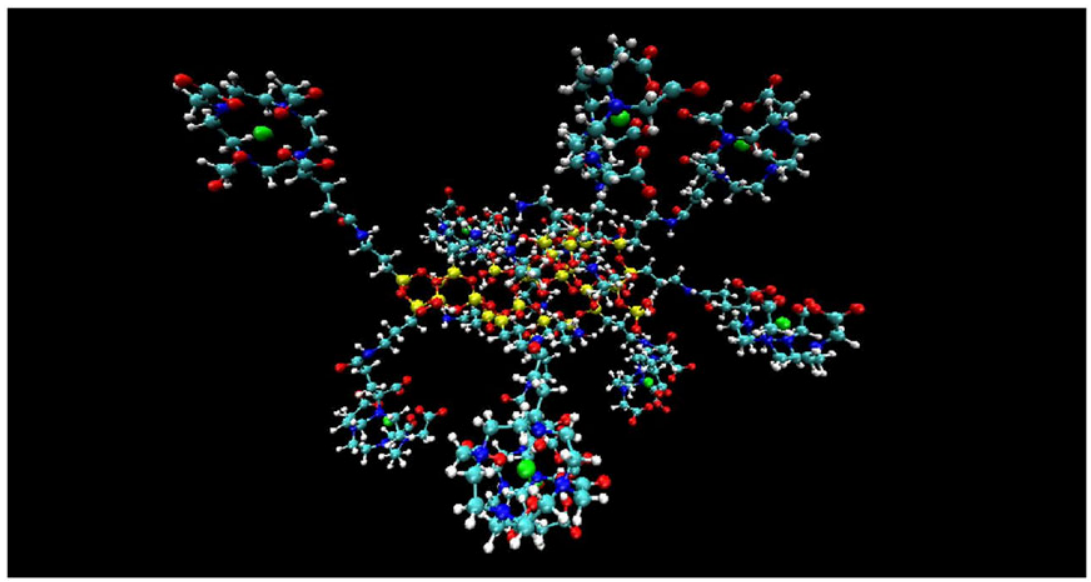

Figure 8. Representation of a typical USRP with a polysiloxane core and DOTA(Gd) species grafted through amide functions (Si yellow, O red, C light blue, $\mathrm{N}$ blue, $\mathrm{Gd}$ green, $\mathrm{H}$ white) (21). 
administration, normalized to the SNR before the administration. For each mouse, the SE was calculated on two axial slices and averaged over these two slices. The CNR in each image was computed as the difference between the average signal in the fibrotic tissue and in the healthy tissue, normalized to the noise. $\triangle C N R$ was calculated as the difference between the CNR before and after the administration of nanoparticles. The extent of fibrotic tissue was assessed on each animal before and after administration of contrast agent when the CNR reached its maximum value. The fibrotic regions were manually contoured. The volume of fibrotic tissue was computed by summing the segmented area from all the lung slices. The contouring of fibrotic regions and the volume computation was performed twice, at an interval of 1 week, in order to evaluate the reproducibility and precision of the measurements.

\subsection{Contrast agent concentration and pharmacokinetic model}

The absolute concentration of the USRPs in the lung tissue as a function of time was derived as explained in Reference 24. In short, the longitudinal relaxation time $\left(T_{1}\right)$ was computed from the SE measurements. The nanoparticle concentration was then obtained from the formula $C(t)=\frac{1}{r_{1}}\left[\frac{1}{T_{1}(t)}-\frac{1}{T_{1}(0)}\right]$, assuming the longitudinal relativity $r_{1}$ of USRPs at $7 \mathrm{~T}$ to be equal to $60 \mathrm{mM}^{-1}$ $\mathrm{s}^{-1}$ and $T_{1}(0)=1.4 \mathrm{~s}$ for the lungs $(41)$.

Following a single oral instillation of the nanoparticles, the concentration-time profile in the lungs was fitted with a onecompartment model with first-order diffusion and elimination rate. The pharmacokinetic model is described by the following formula:

$$
C(t)=A \frac{\tau_{\mathrm{d}}^{-1}}{\left(\tau_{\mathrm{d}}^{-1}-\tau_{\mathrm{e}}^{-1}\right)}\left(e^{-\frac{t}{\tau_{\mathrm{e}}}}-e^{\frac{t}{\tau_{\mathrm{d}}}}\right),
$$

with $\tau_{\mathrm{d}}$ the diffusion time constant and $\tau_{\mathrm{e}}$ the elimination time constant of the nanoparticles from the lungs. $A$ is a constant related to the clearance rate.

All the data fits were obtained using SciDAVis software (http:// scidavis.sourceforge.net/).

\subsection{Histology}

Histopathological analyses were performed on a subgroup of animals on Day 30 on the right and left lungs. Lung tissues were dissected out after cardiac perfusion of saline solution and paraformaldehyde (prepared in PBS at 4\%). Lungs were immersed in a $4 \%$ paraformaldehyde solution for $24 \mathrm{~h}$. Following fixation, the extracted lungs were embedded in paraffin blocks. Every $100 \mu \mathrm{m}$, two $3 \mu \mathrm{m}$ thick sections were cut and enumerated to approximately retain the spatial information. One of the histological sections was stained with hematoxylin-eosin (HE) to assess the general morphology and the other one was stained with picrosirius red for the identification of collagen fibers.

\subsection{Statistical analysis}

For statistical analysis, comparisons of data groups were carried out using the software GraphPad Prism (San Diego, USA). Comparison of the pharmacokinetic parameters (diffusion and elimination times), SE and CNR between bleomycin-treated and healthy mouse groups was performed using a Mann-Whitney test. Significance was fixed at the $5 \%$ probability level. All the data are presented as mean \pm standard deviation for $\mathrm{SE}, \mathrm{CNR}$ and pharmacokinetic (diffusion and elimination) time constant measurements. Error bars of Figs. 3-5 were also provided as standard deviation.

\section{Acknowledgements}

The authors acknowledge the support of the Agence Nationale de la Recherche (ANR) (ANR-12-P2N-0009) for the project Gd-Lung. This study was achieved within the context of the Laboratory of Excellence TRAIL ANR-10-LABX-57. The authors thank Nathalie Senant for her help in histological studies.

\section{REFERENCES}

1. Khalil N, O'Connor R. Idiopathic pulmonary fibrosis: current understanding of the pathogenesis and the status of treatment. Can Med Assoc J 2004; 171: 153-160.

2. Smith M, Dalurzo M, Panse P, Parish J, Leslie K. Usual interstitial pneumonia-pattern fibrosis in surgical lung biopsies. Clinical, radiological and histopathological clues to aetiology. J Clin Pathol 2013; 66: 10831.

3. Bjoraker JA, Ryu JH, Edwin MK, Myers JL, Tazelaar HD, Schroeder DR, Offord KP. Prognostic significance of histopathologic subsets in idiopathic pulmonary fibrosis. Am J Respir Crit Care Med 1998; 157: 199-203.

4. King TE Jr, Schwarz MI, Brown K, Tooze JA, Colby TV, Waldron JA Jr, Flint A, Thurlbeck W, Cherniack RM. Idiopathic pulmonary fibrosis: relationship between histopathologic features and mortality. Am J Respir Crit Care Med 2001; 164: 1025-1032.

5. Raghu G, Weycker D, Edelsberg J, Bradford WZ, Oster G. Incidence and prevalence of idiopathic pulmonary fibrosis. Am J Respir Crit Care Med 2006; 174: 810-816.

6. Meltzer EB, Noble PW. Idiopathic pulmonary fibrosis. Orphanet J Rare Dis 2008; 3: 8.

7. Raghu G, Collard HR, Egan JJ, Martinez FJ, Behr J, Brown KK, Colby TV, Cordier JF, Flaherty KR, Lasky JA, Lynch DA, Ryu JH, Swigris JJ, Wells AU, Ancochea J, Bouros D, Carvalho C, Costabel U, Ebina M, Hansell DM, Johkoh T, Kim DS, King TE Jr, Kondoh Y, Myers J, Müller NL, Nicholson AG, Richeldi L, Selman M, Dudden RF, Griss BS, Protzko $\mathrm{SL}$, Schünemann HJ. An official ATS/ERS/JRS/ALAT statement: idiopathic pulmonary fibrosis: evidence-based guidelines for diagnosis and management. Am J Respir Crit Care Med 2011; 183: 788-824.

8. Rafii R, Juarez MM, Albertson TE, Chan AL. A review of current and novel therapies for idiopathic pulmonary fibrosis. J Thorac Dis 2013; 5: 48-73.

9. Gong LK, Li XH, Wang H, Zhang L, Chen FP, Cai Y, Qi XM, Liu LL, Liu YZ, Wu XF, Huang CG, Ren J. Effect of feitai on bleomycin-induced pulmonary fibrosis in rats. J Ethnopharmacol 2005; 96: 537-544.

10. Egger C, Cannet C, Gérard C, Jarman E, Jarai G, Feige A, Suply T, Micard A, Dunbar A, Tigani B, Beckmann N. Administration of bleomycin via the oropharyngeal aspiration route leads to sustained lung fibrosis in mice and rats as quantified by UTE-MRI and histology. PLoS One 2013; 8: 63432.

11. Lipson DA, Van Beek EJR. Functional Lung Imaging. Lung Biology in Health and Disease, vol. 200. Taylor and Francis: Boca Raton, FL, 2005.

12. Biederer J, Beer M, Hirsch W, Wild J, Fabel M, Puderbach M, Van Beek EJ. MRI of the lung (2/3). Why... when... how? Insights Imag 2012; 3: 355-371.

13. Wild JM, Marshall H, Bock M, Schad LR, Jakob PM, Puderbach M, Molinari F, Van Beek EJ, Biederer J. MRI of the lung (1/3): methods. Insights Imag 2012; 3: 345-353.

14. Wielpütz M, Kauczor HU. MRI of the lung: state of the art. Diagn Interv Radiol 2012; 18: 344-353.

15. Babin AL, Cannet C, Gerard C, Wyss D, Page CP, Beckmann N. Noninvasive assessment of bleomycin-induced lung injury and the effects of short-term glucocorticosteroid treatment in rats using MRI. J Magn Reson Imaging 2011; 33: 603-614.

16. Babin AL, Cannet C, Gerard C, Saint-Mezard P, Page $C P$, Sparrer $H$, Matsuguchi T, Beckmann N. Bleomycin-induced lung injury in mice investigated by MRI: model assessment for target analysis. Magn Reson Med 2012; 67: 499-509. 
17. Jacob RE, Amidan BG, Soelberg J, Minard KR. In vivo MRI of altered proton signal intensity and $\mathrm{T} 2$ relaxation in a bleomycin model of pulmonary inflammation and fibrosis. J Magn Reson Imaging 2010; 31: 1091-1099.

18. Caravan P, Yang Y, Zachariah R, Schmitt A, Mino-Kenudson M, Chen $\mathrm{HH}$, Sosnovik DE, Dai G, Fuchs BC, Lanuti M. Molecular magnetic resonance imaging of pulmonary fibrosis in mice. Am J Respir Cell Mol Biol 2013; 49: 1120-1126.

19. Vande Velde G, De Langhe E, Poelmans J, Dresselaers T, Lories RJ, Himmelreich U. Magnetic resonance imaging for noninvasive assess ment of lung fibrosis onset and progression. Invest Radiol 2014; 49: 691-698.

20. Karmouty-Quintana H, Cannet C, Zurbruegg S, Blé FX, Fozard JR, Page CP, Beckmann N. Bleomycin-induced lung injury assessed noninvasively and in spontaneously breathing rats by proton MRI. J Magn Reson Imaging 2007; 26: 941-949.

21. Bianchi $A$, Lux F, Tillement $O$, Crémillieux $Y$. Contrast enhanced lung MRI in mice using ultra-short echo time radial imaging and intratracheally administrated Gd-DOTA-based nanoparticles. Magn Reson Med 2013; 70: 1419-1426.

22. Glover GH, Pauly JM. Projection reconstruction techniques for reduction of motion effects in MRI. Magn Reson Med 1992; 28: 275-289.

23. Zurek M, Boyer L, Caramelle P, Boczkowski J, Cremillieux Y. Longitudinal and noninvasive assessment of emphysema evolution in a murine model using proton MRI. Magn Reson Med 2012; 68: 898-904.

24. Bianchi A, Dufort S, Lux F, Courtois A, Tillement O, Coll JL, Crémillieux Y. Quantitative biodistribution and pharmacokinetics of multimoda gadolinium-based nanoparticles for lungs using ultrashort TE MRI. Magn Reson Mater Phys Biol Med 2014; 27: 303-316.

25. Schrier DJ, Kunkel RG, Phan SH. The role of strain variation in murine bleomycin-induced pulmonary fibrosis. Am Rev Respir Dis 1983; 127: 63-66.

26. Izbicki G, Segel MJ, Christensen TG, Conner MW, Breuer R. Time course of bleomycin-induced lung fibrosis. Int J Exp Pathol 2002; 83: 111-119.

27. Chaudhary NI, Schnapp A, Park JE. Pharmacologic differentiation of inflammation and fibrosis in the rat bleomycin model. Am J Respir Crit Care Med 2006; 173: 769-776.

28. Negrini D, Passi A, Moriondo A. The role of proteoglycans in pulmonary edema development. Intensive Care Med 2008; 34: 610-618.

29. Egger C, Cannet C, Gerard C, Dunbar A, Tigani B, Beckmann N. Hyaluronidase modulates bleomycin-induced lung injury detected noninvasively in small rodents by radial proton MRI. J Magn Reson Imaging 2014. doi:10.1002/jmri.24612.

30. Driehuys B, Cofer GP, Pollaro J, Mackel JB, Hedlund LW, Johnson GA. Imaging alveolar-capillary gas transfer using hyperpolarized ${ }^{129} \mathrm{Xe}$ MRI. Proc Natl Acad Sci U S A 2006; 103: 18278-18283.

31. Moore BB, Hogaboam CM. Murine models of pulmonary fibrosis. Am J Physiol Lung Cell Mol Physiol 2008; 294: L152-L160.

32. Choi HS, Ashitate Y, Lee JH, Kim SH, Matsui A, Insin N, Bawendi MG, Semmler-Behnke M, Frangioni JV, Tsuda A. Rapid translocation of nanoparticles from the lung airspaces to the body. Nat Biotechnol 2010; 28: 1300-1313.

33. De Vooght V, Vanoirbeek JA, Haenen S, Verbeken E, Nemery B, Hoet $\mathrm{PH}$. Oropharyngeal aspiration: an alternative route for challenging in a mouse model of chemical-induced asthma. Toxicology 2009; 259: 84-89.

34. Lux F, Mignot A, Mowat $P$, Louis $C$, Dufort $S$, Bernhard C, Denat F, Boschetti F, Brunet C, Antoine R, Dugourd P, Laurent S, Vander Elst L, Muller R, Sancey L, Josserand V, Coll JL, Stupar V, Barbier E, Rémy C, Broisat A, Ghezzi C, Le Duc G, Roux S, Perriat P, Tillement O. Ultrasmall rigid particles as multimodal probes for medical applications. Angew Chem Int Ed 2011; 50: 12299-12303.

35. Bianchi A, Dufort S, Lux F, Fortin PY, Tassali N, Tillement O, Coll JL, Crémillieux $Y$. Targeting and in vivo imaging of non-small-cell lung cancer using nebulized multimodal contrast agents. Proc Natl Acad Sci U S A 2014; 111: 9247-9252.

36. Bernstein MA, King KF, Zhou XJ. Handbook of MRI Pulse Sequences. Elsevier: Burlington, MA, 2004.

37. Bergin CJ, Pauly JM, Macovski A. Lung parenchyma: projection reconstruction MR imaging. Radiology 1991; 179: 777-781.

38. Bergin CJ, Noll DC, Pauly JM, Glover GH, Macovski A. MR imaging of lung parenchyma: a solution to susceptibility. Radiology 1992; 183 : 673-676.

39. Zurek M, Bessaad A, Cieslar K, Crémillieux Y. Validation of simple and robust protocols for high-resolution lung proton MRI in mice. Magn Reson Med 2010; 64: 401-407.

40. Lederlin $M$, Crémillieux $Y$. Three-dimensional assessment of lung tissue density using a clinical ultrashort echo time at 3 tesla: a feasibility study in healthy subjects. J Magn Reson Imaging 2014; 40: 839-847.

41. Watt KN, Bishop J, Nieman BJ, Henkelman RM, Chen XJ. Oxygen-enhanced MR imaging of mice lungs. Magn Reson Med 2008; 59: 1412-1421. 